\title{
APORTES PARA LA REFLEXIÓN SOBRE EL FENÓMENO DEL SUICIDIO EN ADOLESCENTES ${ }^{1}$
}

\author{
Orlando Guevara Villalobos*
}

\author{
RESUMEN
}

El presente texto plantea el estudio y conceptualización de una serie de elementos microsociales y más generales que enmarcan el proceso que lleva al intento de suicidio en los adolescentes. Los factores de orden estructural y biográfico que se presentan en la vida cotidiana de los adolescentes suicidas, o mejor dicho, de las redes sociales de las cuales ellos parten para orientar sus acciones en diversas direcciones, así como el conflicto, tensión y dolor anclado en las diversas interacciones de red, enraizadas en los complejos procesos socioculturales y económicos actuales son temas a tratar en el siguiente trabajo.

PALABRAS CLAVE: SUICIDIO * ADOLESCENCIA * JÓVENES $*$ IDENTIDAD * FAMILIA

\section{ABSTRACT}

The following text defines the study and general concepts of a series of general and microsocial elements that englobe the process that lead to suicide attemps in adolescents. The issues that are discussed in the following work include: structural and biographical factors that exist in suicidal adolescents, or in other words, in the social networks from which they reference to orient their actions in diverse ways, as are conflict, tension and pain based in the diverse network interactions, rooted in the complex social, cultural and economical processes of today.

KEY WORDS: SUICIDE $*$ TEENAGE $*$ YOUTH $*$ IDENTITY $*$ FAMILY

\section{INTRODUCCIÓN}

El concepto y la práctica del suicidio adquieren diversas manifestaciones $y$ significación históricas de acuerdo con la(s)

1 El artículo está escrito a partir del trabajo de investigación "Dinámica microsocial del suicidio en adolescentes: un estudio de redes sociales", tesis de Licenciatura en Sociología defendida en julio de 2004. sociedad(es) al que remiten. La categorización utilizada por Durkheim (1972) muestra un claro ejemplo de ello, en la que el fenómeno del suicidio varía con relación a los grados de integración y regulación sociales en diversos

\footnotetext{
* Escuela de Sociología de la Universidad de Costa Rica. / orlangv@gmail.com
} 
momentos de la Europa del siglo XIX. No obstante, estos niveles encuentran sustrato en prácticas concretas que cotidianamente dan sentido, contradicen o desgarran otro conjunto de acciones, normas, ideales, etc. que poseen un carácter significativo para los sujetos, $y$ que paulatinamente convierten el acto del suicidio en una opción.

En nuestras sociedades modernas cierta modalidad del suicidio está vinculada a la barbarie generalizada que brota de ellas. No sólo la observamos en la guerra, la discriminación, la exclusión, sino la vemos también en el malestar individual generalizado. Así la depresión, la desesperanza, y el suicidio toman fuerza en un mundo donde no basta con el odio externado hacia los demás, sino el mismo que se vuelve contra el propio sujeto.

La investigación a la cual atañe esta reseña consistió en el análisis de la configuración del entramado de relaciones o redes sociales en cuatro adolescentes (Thorin de 18 años, Ancalimë de 16 años, Elessimë de 14 años, Elanor de 16 años) que hubieran realizado tentativas de suicidio entre los años 2002-2003, y que se encontraran en tratamiento psicológico en el Hospital Nacional Psiquiátrico al momento de la investigación. Los cuatro adolescentes mantuvieron similitudes en cuanto a su entorno: ubicados en áreas geográficas donde predominan familias de ingresos bajos, y cercanos a barrios urbano-marginales en la provincia de San José. Ningún miembro de la familia de los adolescentes ha llegado a cursar estudios universitarios, y salvo el caso de Elanor, viven con sus madres, que son jefas de familia, separadas o viudas (madre de Elessimë).

El Análisis de Redes Sociales se utilizó como el método para poder describir tanto la estructura como las funciones que cumplen estas redes sociales, al tiempo que se complementó con la reconstrucción de la experiencia social de cada uno de los casos, permitiendo visualizar los ambientes y la dinámica que figura como generadora de frustración y tensión individual, dinamizando a los sujetos implicados en la trama.

El estudio del suicidio supone enfrentarse al dolor, a la experiencia de una subjetividad desgarrada que por su condición misma dificulta traspasar el velo de lo inmediato y aún más observar su engarzamiento a las condiciones objetivas que el mismo suicidio intenta borrar.

Este artículo no busca explicar por completo las condiciones objetivas del fenómeno suicida, sino que trata microsocialmente el contexto de transformación de las formas tradicionales de organización familiar y del universo de valores que da sentido a la familia nuclear, proceso mediado por recientes tendencias socioculturales en relación con los nuevos modelos de producción mundial capitalista y sus consecuencias en la división social del trabajo. Formas tradicionales y/o locales de organización pierden legitimidad ante los estándares del capitalismo globalizado, $y$ entre muchas de sus consecuencias, se genera una variación de la correlación de poder dentro de la red de relaciones cotidianas donde se sitúa el mundo significativo del adolescente, en quien confluye las fuerzas de la tradición y lo moderno, lo homogéneo y lo distintivo, como parte de la construcción de su identidad socio-individual. En el adolescente suicida, este proceso se caracteriza por la abstracción del reconocimiento social $y$ de las necesidades afectivas que forman parte de su horizonte personal, entrando en clara contraposición con las nuevas redes de vínculos, y que resuelve en la tentativa de autoeliminación. Esta tentativa, transitará entre la sensación de futilidad $y$ la protesta violenta ante una sociedad que confina las necesidades del adolescente al olvido, lo niega como sujeto activo, e intenta sumirlo en el océano de la nimiedad y el fracaso social. A continuación algunas anotaciones respecto al método.

\section{REPLANTEANDO EL ANÁLISIS DE REDES SOCIALES}

Este concepto nace de la perspectiva del universo como un entramado de relaciones donde los sujetos son nodos que conforman la red. Requena define la red social como

Un conjunto finito de actores o grupos de actores y las relaciones definidas entre ellos. Es el tejido formado por las relaciones entre un conjunto de actores que 
están unidos directa o indirectamente mediante compromisos, informaciones, etc. (Requena, 2002: 2).

De esta manera, el análisis de estas redes investiga el modelo "de relaciones entre los actores sociales, también como el modelo de relaciones entre los actores en distintos niveles de análisis (como personas y grupos)" (Breiger, 2002: 1). Estas relaciones o lazos, se encuentran determinados por las características estructurales de la red, pues "los participantes se encuentran involucrados en una estructura social - parentesco, grupos de trabajo, círculos de amistad, redes vecinales- que los condicionan..." (Wellman, 2000: 25).

Son en principio, un sistema reticular de cognición y de conductas que preestablecen redes de intercambio desde que nacemos, a partir de los cuales se manifiestan otras redes de intercambio que proporcionan al actor soporte estructural, recursos, acceso a información, a posibilidades y oportunidades dentro de un sistema, $y$ que permiten la conformación de otras redes operativas o concretas, donde se construyen los "conjuntos de acción" (Villasante, 2002: 88). Las redes sociales son, por tanto, conjuntos de relaciones sociales 0 interpersonales que ligan individuos $u$ organizaciones en "grupos".

Estos lazos o uniones, se caracterizan por ser asimétricamente recíprocos, variando tanto en calidad como en cantidad entre dos o más personas, así como se pueden clasificar de acuerdo con la forma y contenidos de los vínculos entre dos actores. Además vinculan a los miembros de una red de forma directa o indirecta, a tal punto que permite la conexión de un sujeto con otras redes y estas a su vez con otras que determinan los lazos específicos. De tal manera que, los lazos indirectos como relaciones complejas "hacen que los miembros de una red formen parte de grandes sistemas sociales, transmitiendo y asignando recursos escasos" (Wellman, 2000: 27) de manera diferencial de acuerdo con la organización y estructuración de las redes. Esto implica una ubicación estructural que determina el acceso a los recursos por parte de los miembros de un sistema social. Asimismo, la reciprocidad y transitividad (lazos indirectos) de los miembros de una red, los vincula a conglomerados densamente interconectados, aunque no posean lazos directos con todos los miembros de la red.

Este tipo de análisis adquiere mayor importancia para este trabajo en tanto permite adentrarse en los contenidos que se transmiten en las relaciones, así como la visualización primera del tejido de relaciones y características de las mismas, que después cobraron sentido en el acercamiento biográfico a las mismas por medio de entrevistas a sus miembros.

\section{EL SUICIDIO Y SU DINÁMICA}

La siguiente es una lectura de ese mundo, donde destacan los rasgos que se articulan en lo que llamamos una dinámica de la desvinculación expresada en las relaciones sociales de adolescentes suicidas, $y$ algunos determinantes socioculturales engarzados en este fenómeno. A continuación la definición de estos rasgos:

LA DILUCIÓN DE LA FAMILIA COMO
HORIZONTE MORAL A PARTIR DE LA
TRANSFORMACIÓN DE LA ESTRUCTURA DE
INTERACCIÓN DEL GRUPO PRIMARIO

Uno de los aspectos generales que se encontró en los casos, consiste en cambios de orden estructural que afectan el funcionamiento histórico de la familia como red social. De esa manera, se presenta una nueva configuración que afecta el grado de regulación y la correlación de poder existente en esta red. En el sujeto I (Thorin) el re-asentamiento de una figura parental - la madre- reconfigura el sistema normativo en un intento por devolverle - a ella - importancia en la red familiar.

Thorin: - La relación ha sido bastante aparte, ya de mi mamá; o sea yo crecí y mi mamá por su lado y yo por mi lado. Sí, entonces no ha sido como muy de compartir entre los dos; digamos, yo nunca le contaba nada a ella de lo que hacía, tampoco la llamaba para contarle nada, o sea, nunca $y$... y qué le puedo decir que no, que no hemos tenido comunicación, 
que mi mamá nunca nos mostró cariño, interés... pero después le dio por jugar de mamá de verdad, pegándonos.

En el sujeto II (Ancalimë), la nueva función del padre genera un desgarramiento en la conformación de la red, al redefinirse la forma en que él se (des)vincula con el resto de la familia $y$ entrando en una clara contradicción con la configuración anterior basada en la labor del cuido, y que posteriormente presenta un distanciamiento-acercamiento afectivo y normativo que deteriora cada vez más su figura como padre. Una forma de visualizar su relación actual es la siguiente:

Ancalimë: - Que mi papá sí, él en cierta forma lo toma por el lado de que, incluso de que 'usted es a la que yo le he dado todo, ¿por qué es así?' Como diciendo, si es a la que he dado todo ¿por qué soy yo así? Pero todo es en el sentido material, más que todo...

No obstante, la madre de ella explica más la dinámica que conllevó a este tipo de configuración:

-Y que le puedo decir, ella era como la hija más chineada por él, jugaban todo el tiempo y nunca le ha faltado nada, pero las cosas fueron mal... es que una vez descubrimos a mi esposo con otra mujer, $y$ desde ese momento las cosas cambiaron en la casa... entonces mi marido se desentendió de todo, me dijo 'usted preocúpese por cuidarlos, por tenerme todo ordenado y prepararme comida, yo me encargo de darle la plata...' el vive aquí pero sólo se encarga de dar plata.

En el sujeto III (Elessimë) la muerte del padre genera el reclamo de la autoridad por los hermanos mayores, que a partir de este cambio estructural buscan regular la vida privada de ella, y en ciertos momentos hasta de su madre; el papel de centralidad que ellos juegan en el proceso de integración de su hermana en las redes exteriores al ámbito familiar genera una sensación de fracaso social por la insatisfacción que genera la mediación de esos vínculos.
Elessimë: - ... obviamente que lo cuidan a uno, pero es que a veces se pasan del límite, o sea lo tratan a uno muy mal, creen que uno es como la esposa de ellos; como ellos no tienen novia entonces se centran en uno, entonces lo tratan a uno muy mal. Imagínese que desde que tenía como siete años me acuerdo que ellos siempre le han dicho a uno palabras ya... groseras...

Elessimë: - Lo que me afectaba era que mis hermanos fueran los que lo pensaran así, porque, o sea, cuando sabe que las cosas no son ciertas entonces uno como que no le importa, pero yo escuchaba a mis hermanos que más bien eran ellos los que les decían a mis amigos que yo era una... ya así. Entonces eso era donde yo me deprimía más, era como que ellos siempre me daban una mala reputación.

Por último, en el caso atípico del sujeto IV (Elanor) el nuevo tejido familiar no regula las pasiones individuales, vacío que se extiende con la inserción de la madre al mundo laboral en un intento por aumentar la calidad de vida de la familia, $y$ al mismo tiempo por el sistema de autorregulación que los padres - por convicción propia- promueven en la crianza de sus hijos, y cuyos efectos Durkheim expresa de la siguiente manera “... los apetitos, al dejar de estar contenidos por una opinión desorientada, ya no saben donde están los límites ante los cuales deben detenerse. [...] en ese caso, sus mismas exigencias hacen que resulte imposible satisfacerlas" (1972: 202). Las historias significativas de su vida personal siempre giran en torno a lo mismo, frente a una postura un tanto pasiva de sus padres:

Elanor: - Bueno lo que yo me acuerdo que el año pasado en octubre me iba a tomar, $y$ yo venía como desde las seis de la noche toda borracha...

Elanor: - ... a todos los conocí bailando... o sea, bueno a uno lo conocí en Pueblo Viejo... Después de eso anduve con un mae que conocí en Planet Mall... 
Ante esta situación podría objetarse que no existe familia que no haya sufrido este tipo de cambios en algún momento de su vida, generándose un ambiente que pueda favorecer la conducta suicida. Sin embargo, el problema no radica propiamente en el cambio estructural, sino en las características de los lazos familiares $y$ otras redes a partir de estos cambios, además del conflicto e inestabilidad que ello puede provocar en una red que - por lo general-en su fase temprana primaron los vínculos afectivos y la función del cuido. En otras palabras, en las formas e intensidad que toma la ruptura $y / 0$ reconfiguración de lazos significativos.

Por lo tanto, si en el proceso de reformulación de las relaciones en el interior de la familia los nuevos contenidos de los vínculos no llegan a suplir las necesidades afectivas, de apoyo, contención y reconocimiento de los adolescentes, se favorece la generación de situaciones en el seno del hogar que producen insatisfacción, al tiempo que crece la sensación de futilidad, angustia y enojo por parte de los mismos.

De acuerdo con Durkheim, la vida social “... provoca en las personas la adquisición de valores con base a los cuales se toman las decisiones y desarrollan su comportamiento. Esta existencia que tiene lugar en la sociedad genera en los seres humanos una necesidad de contacto, un estímulo que los encamina hacia la comunicación" (1999: 49). Al comparar el estado de las redes sociales de los jóvenes en cuestión con esta afirmación, se logra observar que en los casos estudiados, la necesidad de contacto no se satisface en la medida que las características de estas redes más bien alimentan la desvinculación en detrimento de la cooperación. El grupo familiar como red de contención en Thorin y Ancalimë es sumamente débil. No existen prácticas que involucren a la familia como grupo, aunque sea entre unos pocos, así las relaciones transitan entre la indiferencia $y$ la hostilidad ante la invasión de espacios considerados como privados. En otras palabras no existe cohesión familiar, hablamos de un grupo unido solamente por relaciones filiales $y$ de intercambio, donde la afectividad transita en relaciones muy tensas de amor $y$ odio, $y$ donde el conflicto busca solucionarse parcialmente con la indiferencia; son reiterados en ambos casos, las alusiones a que cada uno vela por sí mismo, $y$ donde nadie busca involucrarse entre sí, pues es común que ello produzca enfrentamientos fuertes. En este sentido toma relevancia lo expuesto por Tübert y la caracterización de la estructura familiar, donde encontramos “... indiferenciación e indiscriminación entre sus miembros, y esta a su vez se vincula con el fracaso de la función paterna" (1982:102). Al final parece que estamos frente un grupo de individuos que no se identifican entre sí, donde los jóvenes definen sus relaciones en función de la desvinculación, pero aunque se perciban como seres aislados de los demás queda claro que ese distanciamiento esconde experiencias de dolor y frustración por el estado deteriorado de las relaciones en una red familiar que se encuentra desarticulada. La vinculación provoca dolor, y su antípoda el aplacamiento de la tensión, pero en su realización se encuentra a sí misma como desgarramiento.

En el caso de Elessimë los vínculos familiares están supeditados a la autoridad. Las prácticas que se realizan se encuentran subordinadas a los deseos de los hermanos mayores, $y$ la madre no logra ejercer una función estabilizadora entre el deseo de autoridad de los hermanos, las necesidades de Elessimë y su papel como madre de ellos. Al mismo tiempo, esta excesiva regulación familiar frustra cualquier intento del sujeto de ligarse satisfactoriamente a los grupos de pares, los cuales como menciona Meler (1998) son organizadores de la vida social de los jóvenes, donde según Shorter (tomado de Burin y Meler, 1998) también se privilegian los aspectos emocionales de los vínculos. Son comunes en ella las historias sobre el control que ejercían ellos en su vida, acosándola y controlando cada una de sus salidas fuera de su casa. El carácter autoritario de sus hermanos, queda fielmente expresado en el siguiente pasaje “... es que ella [hermana mayor] como es mujer entonces uno le cuenta cosas ya, que jamás le voy a llegar a contar a mis hermanos, porque quién sabe qué me hacen" (cursiva nuestra).

En los tres primeros casos se observan relaciones intrafamiliares donde pesa una actitud negativa $y$ hostil entre ellos y los demás miembros, y - salvando las diferencias contextuales- donde imperan figuras parentales que 
estimulan o están al margen del conflicto y el trato desigual entre los miembros del grupo familiar, comportamiento que viene intrínseco a la ausencia o débil presencia de marcos normativos, causado $y / 0$ reforzado por padres que no logran asumir posiciones claras y concretas ante los problemas diarios, al igual que responsabilidades:

Ancalimë: - _... el día en que me tomé las pastillas ella [hermana mayor] pasó todo el día gritándome y diciéndome un poco de cosas... y es que usted no sabe, de hecho yo andaba con una cólera porque todo el mundo me pasaba reprochando un montón de cosas y que yo 'era esto y era lo otro', entonces... bueno, $y$ parte del problema había sido lo del novio de [hermana mayor]... es que usted no sabe, si a mí hay algo que no soporto y que no les puedo perdonar es que mis papás se pusieran a favor de ese mae, $y$ lo peor de todo es que después de lo que le hizo a mi hermana lo siguieran dejando entrar a la casa... y la otra como si nada también...

Ancalimë: - ... Mi papá se puso como loco y agarró el revólver, y 'él iba a matar a todo el mundo', se iba a matar a él e iba a matar a todo el mundo, iba a matar hasta a mi novio...

Thorin: - _.. recuerdo una vez que estaba mi padrastro... bueno es que yo llegué tarde, y él estaba acostado en el sillón, y yo llegué y había un plato y que tenía cocaína. Entonces yo agarré el plato y lo tiré afuera; $y$ le hago yo 'mae, sálgase de mi vida, yo no quiero verlo, usted es un cerdo - o sea-, cómo va a venir a hacer esto a mi casa'. Mi mamá ahí llorando, y yo le decía mami 'no me hable, usted es una ignorante, como va a andar con un hombre así' le digo yo... ya, 'ya no quiero saber de usted... yo a usted la odio" le decía a mi mamá, entonces volvieron los problemas.

Madre de Elessimë: -Ellos le dicen a ella, ¿a usted le gustaría que a usted le cataloguen como la que no vale nada, o la puta del barrio?

Thorin: - _... ella estuvo ahí cuando vio que él se me tiró encima que me agarró y me pegó; llego a la casa, $y$ le hago 'ves, yo no quiero a ese hombre más aquí', dice mi abuela 'no no no, no me traiga este hombre más a esta casa'. Resulta que ya mami ya la agarra conmigo porque le dijeron que no trajera más a ese man, porque para ella es más importante el hombre que los hijos, cien por ciento... bueno resulta que ya, le hago 'ma, pero vio usted que él tuvo la culpa - le hago-. - No no, yo vi que fue usted el que tuvo la culpa, que usted comenzó. Yo pensé que mami me iba defender a mí y que iba como a rechazar al hombre; se quedó con él después de lo que yo le dije, y ahí bajé el demonio y sí, así están las cosas, y mi mamá al otro lado y yo me sentí como una mier$\mathrm{da}$, entonces yo me vine muy obstinado $y$ se me vinieron esas depresiones y ya uno sale a la calle a fumarse un cigarro, todo humillado...

La red familiar no logra dar bases de apoyo, sino que obliga al sujeto a buscar seguridad y apoyo en otros grupos; en ese sentido la absorción de los momentos conflictivos en el seno familiar y la atmósfera que se genera en ella, lejos de reducir, refuerza la brecha generacional e invita a los jóvenes a buscar para su realización otras redes. En el cuarto caso, correspondiente a una red aparentemente armoniosa, se da un distanciamiento de la red familiar en la medida que la acción individual cada vez se legitima por encima de cualquier marco normativo, en medio del vacío que deja la incorporación de los dos padres al mundo laboral, $y$ un método de crianza que se mantiene intacto y genera oposición, a pesar de la nueva configuración de las relaciones. Se hace evidente una disolución de los horizontes entre lo que se puede o no hacer, aunque no responda directamente a las circunstancias de los otros casos, sino que esta vez la rutina determinada por el ritmo de vida laboral y los quehaceres del hogar terminan haciendo mella en las fuerzas 
físicas y psicológicas de las figuras parentales, hecho que al final recae en indiferencia familiar, en desentendimiento de la regulación moral, $y$ en el desdibujamiento de sus horizontes. Tal retirada de la familia favorece finalmente la privatización de los espacios de interacción.

La poca comunicación se convierte en una constante ya que no solo afecta al grupo familiar, sino que se extiende a los diferentes grupos sociales con los cuales los tres primeros jóvenes se relacionan. Más específicamente, en el caso de Thorin se notan grupos de red cuya relación va desde lo "no tan cercano" a lo "inexistente"; en el segundo caso, si bien el grado de densidad, cantidad y relación de grupos son mayores, predomina la distancia y poca cercanía entre ellos, reflejando grupos que se encuentran en tensión; situación de la que difícilmente puede escapar Ancalimë. En el primer caso los vínculos son pobres y de contenidos simples, siendo una persona la única que le genera un grado de confianza a Thorin, las demás personas que conoce no le inspiran confianza y se limita a compartir unas cuantas actividades de ocio debido - como ya se había mencionado- a la dinámica grupal, donde predominan las bromas, burlas y el sarcasmo. En el segundo caso impera ante todo la tensión intergrupal, $y$ los conflictos generados entre redes, así la separatividad se une al conflicto. Hasta podría plantearse como un conflicto de poder, las prácticas o actividades con los grupos de amigos y los problemas con la familia, devienen de marcos normativos desgastados a partir de los cambios de orden estructural en la red familiar, ejercidos por figuras sin autoridad moral y por la maleabilidad de sus criterios normativos. Esta situación que sucede de una manera un tanto similar en el caso de Thorin, aunque el tema más recurrente en él es la relación ambigua donde predominan los aspectos negativos que en su adolescencia tiene con la madre, producto del conflicto $y$ del abandono no solo físico sino emocionalmente de ella, así como la separatividad radical que sufre el grupo familiar y la frustración que ello genera.

Thorin: - Teníamos problemas en la casa, esa gritadera y esa discusión, me pasaban pegando, $y$ me gritaban 'usted que es un malcriado, un endemoniado, un drogadicto' que aquí, que allá. A veces me gritaron en un momento de cólera que mejor ni hubiera nacido, que es igual a su padre.

Ancalimë: - Mi papá, es que a veces nos vemos y pasamos agarrados del pelo, a mí no me gusta que se meta conmigo por que yo no me dejo y él ha hecho un poco de estupideces en la casa... él no tiene por qué meterse en vida, con mi novio, ni con mis cosas.

Mientras los hilos de estas dos redes se desmoronan, los vínculos de Elessimë son asfixiantes, de tendencia unidireccional, $y$ por ende, donde el espacio reducido limita la capacidad de acción, permitiendo una actividad apenas marginal dentro de su propia red familiar y social. Aquí no hay acción comunicativa, ese privilegio queda reservado a sus hermanos mayores, quienes tienen la capacidad de mediar e incidir en las relaciones Elessimë-amigos, poder utilizado para la construcción de una imagen negativa (de mujer callejera) de ella en las redes en que se desenvuelve, $y$ la desgracia que genera los vínculos poco satisfactorios, reforzando así junto a un fracaso en el colegio $y$ el malestar de la pobreza una sensación de rechazo social e insignificancia.

Elessimë: -yo sentía como que mi vida iba a ser siempre lo mismo, o sea, como que siempre iba a estar sola, como que nunca me iba a llegar a adaptar, como que me sentía rechazada por la sociedad, y como que ni ganas de vivir.

A ello se le suma una infancia donde los conflictos entre padres devinieron en cambios constantes de domicilio, lo que impidió que tuviera un lugar estable que le permitiera encontrar amistades, intimar con compañeros de escuela reforzando el desarraigo que ella siente del mundo (The CQResearcher, 2004: 130). Al respecto, su madre expresa que

-... usted no sabe todo lo que ese hombre nos hizo, donde quiera que íbamos 
siempre nos perseguía, yo pasaba angustiada de que él se diera cuenta a donde nos habíamos ido a vivir, porque me amenazaba con que se iba a llevar a mis hijos.

En Elanor se da una situación curiosa tanto en esa línea como con respecto a la configuración de los lazos familiares y los contenidos que se transmiten. En un principio la comunicación que existe entre ella y su red familiar se vio coartada por la inserción materna al mercado laboral, circunstancia que relaja los vínculos familiares tanto a un nivel afectivo como normativo. Posteriormente, se da un proceso de apertura donde se intenta rescatar a la familia mediante la discusión. Primero que todo, la apertura a la discusión de temas como sexualidad, drogas, desarrollo social y apoyo familiar tardó algunos años en gestarse, lo suficiente para que Elanor ya hubiera experimentado por su propia cuenta este tipo de cosas. Las vías de comunicación logran crearse y fomentarse a raíz de estas experiencias, donde la posición de los padres se fija en su desacuerdo a las actividades de Elanor fuera de su casa. Sin embargo, la puerta que llevó a Elanor a estas experiencias sigue abierta como antes, solo que con una diferencia, al seguir estos espacios abiertos sin regulación alguna, aún después de la desaprobación familiar, puede dar por sentado que la ausencia de castigo implica la no existencia de crimen alguno, $y$ por lo tanto, supone a un sujeto libre de realizar todos sus deseos.

-... ya yo en un momento llegué en que mi mamá me regañaba porque yo duraba tres horas hablando con AO y a mí no me importaba, y yo... a mí no me importaba yendo con él todo el día, yo pensaba en él, o sea fue una obsesión más que todo...

-... yo jamás me había llegado a descontrolar tanto, y eso como llegar y delante de mi hermano tomar y fumar, si mi papá no lo hace, yo nunca lo haría... mis papás no fuman, ninguno, y ya, yo me acuerdo que mi hermanito estaba ahí y yo fumaba así como si nada, o sea a mí no me importaba, o sea no era yo entonces ya.
De esta manera, las relaciones comunicativas de Elanor con sus padres (especialmente con la madre) se configuran con base a la sensación de estar fuera del alcance nómico de la red familiar, $y$ por la predominancia de una posición poco reflexiva sobre la vida de Elanor por parte de las figuras parentales, $y$ sobre todo el distanciamiento que el mundo laboral supone de las relaciones dentro de la red familiar, pues entre las extenuantes horas de trabajo y los quehaceres de la casa, la función paterna y materna queda reducida a proveer materialmente a sus hijos y las prácticas de cohesión se vuelven cada vez más difíciles de lograr. De tal modo, se fomenta la desvinculación y la sustitución de espacios que antes correspondían a la red familiar por nuevas prácticas con otras redes o simplemente nada. En su relación con otras redes queda clara la falta de confianza para expresar sentimientos y comunicar problemas, gracias a configuraciones similares a las existentes en el caso Thorin.

Resumiendo, en los cuatro casos existe un cambio de orden estructural en la red familiar, que afecta los antiguos vínculos de asociación y los reconfigura de acuerdo con las nuevas funciones y circunstancias que imperan en el nuevo contexto. Esto supone un cambio en las prácticas de integración y la función reguladora de la familia, así como en su función de apoyo, en el proceso de integración social, moral, etc.

Las nuevas configuraciones transitan entre normatividad e integración. Los cambios que inciden en la capacidad reguladora de las redes familiares pueden presentar dinámicas diferentes, pudiéndose identificar por un lado redes familiares cuya capacidad de retención incuestionable (basadas principalmente en el control estricto de las relaciones y el no reconocimiento de los miembros subordinados como sujetos, condiciones visibles en el caso de Elessimë) se vuelve sofocante, mientras que en otras (Thorin, Ancalimë) la función de regulación provoca conflicto, cuando el marco normativo se reconfigura, se vuelve inconsistente $y$ objeto de cuestionamientos. Al final, el producto será el mismo, la asfixia del sujeto ante dos dinámicas reguladoras similares, aunque matizadas desde dos momentos distintos, uno 
en el esplendor de su rigurosidad, y otro, en el momento de su desplome.

Ancalimë: - Los fines de semana que talvez salimos [los amigos] a algún lado, o talvez qué, a veces en el cole cuando tengo trabajos paso toda una tarde haciendo trabajos pero en la noche siempre salgo, fijo porque si no me estreso, me sofoca demasiadísimo; estar encerrada en la casa no puedo... en mi casa, la relación es muy [desahogo de angustia], el ambiente casi siempre es muy pesado.

Esta nueva configuración de las relaciones causa frustración e insatisfacción entre sus miembros, conflictos interminables, $y$ un ambiente que lejos de brindar seguridad provoca tribulación y soledad.

\section{$\diamond \quad$ LA DINÁMICA SUPERFICIAL Y EXCLUYENTE DE}

LAS RELACIONES ENTRE PARES,

Y LA INSATISFACCIÓN QUE ELLAS PROVOCAN

Irene Meler (1998) considera que los grupos de pares mantienen una función primordial en la medida que permiten organizar alternativamente la vida de los jóvenes, a lo cual agregaríamos es motivo de satisfacción en tanto que el sujeto tenga capacidad de orientar estas relaciones sobre la base de su propia y espontánea interacción cotidiana. Es el mundo más que dado, se presenta, como lo construido en la interacción, donde los sujetos mantienen algún nivel de protagonismo $y$ donde surge con mayor fuerza la posibilidad de reconocimiento como sujetos activos. En complemento, la afirmación que Shorter (1998) da sobre la primacía de lo afectivo en los vínculos entre pares, refuerza la densidad $y$ la identidad de estas redes sociales.

En los casos estudiados, el deterioro de los vínculos familiares supone una variación en la correlación de poder que se despliega en ellas. En estas circunstancias, la configuración de las redes de compañeros $y$ amigos puede jugar un papel decisivo, en la medida que los contenidos que se transmiten ayuden al desarrollo de la cooperación y solidaridad de los jóvenes y a reafirmarse socialmente mediante prácticas sociales satisfactorias, que pueden basarse en el reconocimiento de sí mismos y su autonomía (Krauskopf, 1999), situación que claramente no se logra en los casos estudiados. Podríamos afirmar en este sentido lo mismo que Tübert con respecto a una determinación estructural ligada a estos intentos de suicidio, en lo referente a "... a la falta de un lugar en el cual el adolescente pueda definirse y reconocerse como sujeto, tanto en la familia como en la sociedad" (1982: 102).

En las redes de pares estudiadas, las condiciones genealógicas de los marcos de acción y percepción transitan por derroteros similares. Aquí se destacan (A) los efectos de una dinámica familiar estresante que lleva a configurar dinámicas entre pares teniendo como un elemento motivacional el alivio de las tensiones familiares, (B) la construcción de un horizonte completo como alternativa frente al ambivalente noreconocimiento del grupo familiar y su función orientadora de las acciones individuales.

La naturaleza de la asociación con las redes informales corresponde a dinámicas grupales que lejos de dar apoyo y reconocimiento, generan frustración por el predominio de prácticas basadas en la exaltación de la diferencia, la exclusión y la interacción superficial, que deviene en riesgo en tanto no hay conciencia de la acción y sus consecuencias.

Mejor amiga de Elanor: - ... al menos con la gente que andaba Elanor antes, eran solo hombres, $y$ eran muy burlistas, trataban de hacerlo sentir mal a uno...

Elessimë: - ... están mis amigos de toda mi vida, que a esos los conozco desde pequeñitos, esos ya, tienen su, su ritmo raro, porque un tiempo están bien con uno, 'ay Elessimë' y todo, $y$ cuando ve y se da la espalda están 'esa vieja tal cosa', y están inventando cosas de uno, entonces me aparté mucho de ellos, porque también eran esos los que se llevaban bien con mis hermanos.

Thorin: - . . ese buen amigo que yo tengo sí ha estado en varias cosas, ese sí lo puedo contar, pero diay, yo no puedo confiar 
en otra persona porque tal vez puede ser que yo confíe mucho y después lo decepcionen a uno.

Mejor amigo de Thorin: - ... es que mae yo le voy a decir una vara, aquí la gente es media rara, usted no puede confiar en ellos porque lo agarran para chingarlo a uno y comérselo a uno con otra gente, además poco de bronqueros que lo meten a uno mierdas raras, entonces es como que mejor andarles de lejitos, por eso me llevo bien con Thorin porque con esos maes nada que ver.

Elanor: - ... de fiesta. Un fin de semana completo, [...] y no se ya tenemos todo planeado para hacer una fiesta el sábado $y$ domingo, $y$ el lunes que es quince de setiembre $y$ es feriado... ir a tomar...

Esta frivolidad en las relaciones con otras redes y sus prácticas basadas en parte en la exaltación de aspectos discriminatorios de sus propios miembros o prácticas que por su edad son socialmente señaladas, difícilmente ofrecen condiciones de soporte ante posibles cismas en la vida de estos jóvenes. Es interesante observar en estos jóvenes realizadores de tentativas de suicidio, un distanciamiento de aquéllos que constituyen sus lazos significativos, esta ambivalencia radicaba en la insatisfacción de las formas de interacción, de los derroteros inesperados que las relaciones amistosas toman y de la sensación de no existir una dirección por dónde orientar mutuamente las acciones en el universo de identidades $y$ horizontes morales. De esta forma las expectativas de red se truncan en la medida que los contenidos transmitidos en los vínculos no logran siquiera reproducir lejanamente la imagen edénica del pasado, es decir, la sensación de bienestar en el pasado idealizado frente a un presente que se muestra hostil.

Así, un campo donde el reconocimiento, la amistad y el control relativo de las relaciones se encuentra hiper-valorado (como la única opción "razonable" de superar la angustia devenida del conflicto entre el ideal familiar y la práctica familiar concreta) en combinación con prácticas sociales insustanciales, cualquier signo de desbordamiento sistemático del sujeto por lo real implica la anulación del mismo, de la misma manera que una casa construida sobre la duna de un desierto desaparece con la siguiente tormenta de arena.

No obstante, existe un caso particular donde siquiera se llega a eso, donde la excesiva regulación familiar frustra cualquier intento del sujeto de ligarse satisfactoriamente a los grupos de pares. Aquí la reconfiguración de las relaciones familiares no llega a provocar un despegue del campo familiar, donde el carácter excesivamente normativo de las relaciones amarra y coarta cualquier posibilidad de acción. En este caso no hay una autoridad deslegitimada, sino una autoridad que tensa los hilos y sofoca a sus miembros, inversamente en consonancia con la afirmación de Durkheim cuando escribe que "... cuando decimos que es necesaria una autoridad para imponerlo a particulares, de ningún modo queremos decir que la violencia sea el solo medio de establecerlo [...] más es preciso que ese poder sea obedecido por respeto y no por temor" (1972: 201).

Elessimë: - ... uno no puede salir a la esquina, porque ellos andan diciendo que uno anda haciendo cosas. Que uno anda, como le explico, que uno anda con hombres, es que ellos como no tienen novia piensan que uno es como de su propiedad.

\section{$\diamond \quad$ LA CENTRÍFUGA DE LA PRODUCCIÓN ECONÓMICA} Y LA EXPERIENCIA EXCLUYENTE DEL CONSUMO

La incertidumbre y frugalidad económica presente en las familias, causa que el sistema productivo se convierta en un factor activo a tomar en cuenta, sobre todo por su capacidad de transformar las relaciones familiares. El fenómeno de "abandono de la familia" comienza a gestarse con la salida de las figuras parentales de su casa, $y$ que se traduce en situaciones vivencialmente difíciles para los miembros de la red familiar (abandono, autoridad deslegitimada, ausencia de prácticas de cohesión, etc.). Esta experiencia subjetiva que se da en el entorno familiar $y$ se extiende en las relaciones 
con otras redes sociales queda disociada de las expectativas de vida de los jóvenes, aumentando la sensación de desconfianza social e inseguridad ontológica.

Ello se da en un contexto socioeconómico que obliga a los padres y hasta a algunos de los hermanos a trabajar para suplir las necesidades básicas para la subsistencia, como se menciona en los casos de Thorin y Elessimë, y/o para poder tener más holgura económica como sucede con Ancalimë y Elanor respectivamente. Ello tiene un efecto particularmente degenerativo en lo referente a los vínculos familiares, en la medida que la lucha por la subsistencia y un nivel de vida estable obliga a los padres $y$ otros familiares a insertarse en el mercado laboral con condiciones productivas que en algunos casos toma un matiz sobre-explotador, descuidando inevitablemente la función orientadora $y$ de apoyo hacia los hijos, $y$ hacia la dinámica de la familia como grupo, en otras palabras un fenómeno en el cual "la familia abandona a sus miembros" (Shorter, en Burin y Meler: 1998). Así como en el siglo XIX el capitalismo industrial llegó a destrozar los lazos entre la familia y la comunidad, el contexto social y económico actual conduce al "desarraigo" de los miembros de la familia.

Esto nos lleva a retomar aunque sea superficialmente el papel del aspecto cultural $y$ económico, en relación con las formas de malestar socio-individual donde sitúo este fenómeno del suicidio. El cumplimiento de las promesas de consumo que ofrece la sociedad y/o la búsqueda por mantener un nivel de vida medianamente digno obliga o supone una reconfiguración de las relaciones familiares en la medida que la madre sale del hogar a trabajar, $y$ la tensión entre el adolescente $y$ las figuras parentales en tanto que se vive la realidad de la imposibilidad de participar "plenamente" en una economía de consumo.

La frustración que genera la sensación de fracaso o conflictividad en la vida general, tanto en los vínculos con la red familiar como en las relaciones con otras redes, y carencia de vínculos plenos en la acepción de Giddens, puede reforzar una tendencia importante de apuntar: la necesidad del consumo como fórmula de integración social y satisfacción individual.
Bauman explica que "las necesidades individuales de autonomía personal, definición propia, vida auténtica o perfección de la persona se transforman en necesidad de poseer $y$ consumir bienes ofrecidos por el mercado" (Giddens, 2000: 251) esto, ante lo que Marcuse definiría como el carácter totalitario de una administración donde "una industrialización más efectiva puede servir para la restricción y manipulación de las necesidades" (1969: 40), así se lograrían determinar los deseos de un individuo, envueltos en el marco mediático del mercado. De forma constante y puntual, especialmente en los relatos de los padres $y$ algunos de los amigos, se hace presente la exigencia de los jóvenes -en los tres primeros casos se da con especial fuerza- por satisfacer sus necesidades de consumo, al tiempo de un continuo reproche tanto a la familia como a la vida por su condición económica desfavorable. De esta manera suponemos que se busca mitigar el dolor mediante el consumo de bienes, $y$ su posesión son sucedáneos de una auténtica o más estable satisfacción posible en otras condiciones. Sin embargo, la realidad de la limitación y la exclusión potencian la insatisfacción, tanto de sus vidas como de su relación con las figuras parentales.

\section{PARA FINALIZAR: AMBIVALENCIA Y LUCHA}

Los procesos descritos permiten capturar los movimientos entre fuerzas subjetivas $y$ redes estructuradas cuya relación y particular tensión da sentido a los actos de los adolescentes suicidas. Puede visualizarse un proceso en el plano de integración familiar que afecta particularmente a los jóvenes. En él, las prácticas familiares poseían un relativamente alto nivel de coherencia con el universo de valores que dan sentido a la vida familiar, lo que favorecía procesos de ambivalencia poco polarizados. Estos valores relacionados con la función del cuido y la transmisión recíproca de afectividad pierden sentido a partir de los violentos cambios estructurales o procesos dolorosos de desestructuración que reformulan las funciones sociales, donde las nuevas prácticas entran en contradicción con el universo de sentido de sus miembros $y$, con un particular efecto en los 
más jóvenes, propensos a sufrir por su dependencia material y afectiva de las figuras parentales. Una variación del mismo lo encontramos en un tejido familiar, que diluido en el conflicto encuentra su sentido en la medida que la necesidad material es más fuerte que la afectiva, destierro subjetivo que sólo logra su regreso en la forma del odio, desesperanza y el reclamo de una vida mejor.

El dolor que este tipo de configuraciones familiares genera se complementa con el fracaso social de las relaciones entre pares $y / 0$ la interacción insustancial, casi mecánica con aquellas personas que constituyen las redes sociales dentro de las cuales se desenvuelven estos jóvenes. De esta manera, la dinámica de la desvinculación encuentra su punto cumbre en la hipostatización del individuo como fuente de ruptura con ese mundo que traicionó las esperanzas $y$ expectativas del mismo. Sin embargo, lo complejo del asunto lo vemos en la contradicción de esta especie de ideal presente en acto y pensamiento del adolescente suicida con su estado de dependencia - particularmente poderosa en la niñez $y$ adolescencia, $y$ que permanece en menor grado en la juventud tardía - de esa misma realidad, la única en la que ha aprendido a desenvolverse, insuflando inevitabilidad.

En tales circunstancias, el proceso de construcción de una identidad socio-individual se ve mediado por (A) una red familiar que transita rápida e irreflexivamente entre retención y expulsión, rompiendo con todos los esquemas normativos y cognitivos pasados, radicalizando las relaciones amor-odio entre figuras parentales e hijos, $y$ (B) por los precarios lazos sociales que impiden los mecanismos de apropiación de una realidad cambiante o que favorece su interiorización como aplastante destino. Lo anterior en medio de un proceso de cambio fisiológico que no podemos obviar, pues la arremetida de los impulsos internos demanda también una reconceptualización del cuerpo $y$ de la identidad en relación con él. El círculo se completa con la ausencia o ineficacia de mecanismos para manejar o hacer más soportable el dolor y la frustración, ampliamente ligados con la creación de espacios sociales de interacción que den seguridad a los adolescentes. Al final la apología del individuo no basta para aprehender una realidad que trasciende en todos los sentidos al individuo mismo.

Estas tendencias bien se gestan en la dinámica interna de las relaciones cotidianas, pero se encuentran determinadas por condicionamientos socioculturales que ejercen presión sobre las familias y el mundo cotidiano de los jóvenes. En este sentido, existe un contexto posibilitador a partir de un tejido de relaciones que en su despliegue genera frustración y desgarre, coartando el manejo de las emociones ante situaciones reiteradas de estrés, o experiencias que traspasan los medios subjetivos disponibles de aprehensión y brego de la realidad.

En Costa Rica, la reflexión sociológica en torno a las distintas manifestaciones del malestar social ha premiado ciertas discusiones de orden político, más palpable y tangible que el contorno borroso de la subjetividad, su conformación, y su deformación en un marco de inseguridad y desesperanza. El objetivo de la reflexión presente es ofrecer un aporte a futuras investigaciones en torno al fenómeno del suicidio, pues esta contribución es una mirada rápida detrás del velo del acto suicida. Actores, fenómenos y órdenes instituidos como los medios de comunicación masiva, el orden económico legitimado en el principio de consumo, y sus implicaciones en la construcción de la subjetividad, la generación de malestar e insignificancia social, constituyen elementos de suma importancia que deben tomarse en cuenta. Así mismo, el abordaje conjunto de las Ciencias Sociales, especialmente en los efectos que la institucionalización de lo social desgarrado tiene sobre las estructuras psíquicas de los sujetos, ampliaría los horizontes del conocimiento, permitiendo comprender $y$ articular las principales interrogantes acerca del fenómeno del suicidio.

\section{BIBLIOGRAFÍA}

Breiger, Ronald R. "Analysis of Social Networks". En: Melissa Hardy y Alan Bryman. Handbook of Data Analysis, Sage Publications. 2002. 
Burin, Mabel. "La relación entre padres e hijos adolescentes". En: Burin, Mabel; Irene Meler Género y familia: poder, amor $y$ sexualidad en la construcción de la subjetividad, Buenos Aires, Editorial Paidós. 1998.

Krauskopf, D. "El desarrollo psicológico en la adolescencia: transformaciones en una época de cambios". En: Adolescencia y salud. Volumen 1, Nro. 2. 1999. pp. 23-30.

Durkheim, Emile. El suicidio. Tercera edición. Buenos Aires, Schapire Editor.1897. $315 p$.

Giddens, Anthony. Modernidad e identidad del yo: el yo y la sociedad en la época contemporánea (3era edición). Barcelona, Ediciones Península. 1991. 299p.

Guevara, Orlando. "Dinámica microsocial del suicidio en adolescentes: un estudio de redes sociales". Tesis para optar por el grado de Licenciado en Sociología. 2004, 219p.

Marcuse, Herbert. El hombre unidimensional: ensayo sobre la ideología de la sociedad industrial avanzada (4ta edición). México, J. Mortiz. 1969, 274p.

Meler, Irene. "La familia, antecedentes históricos $y$ perspectivas futuras”. En: Burin, Mabel e Irene Meler: Género y familia: poder, amor y sexualidad en la construcción de la subjetividad, Buenos Aires, Editorial Paidós. 1998.

Requena Santos, Félix y Avila, Manuel. "Redes sociales y sociolingüística". En: Estudios de Sociolingüística. Vigo, Volumen 3, Nro. 1, 2002, pp. 71-90.

Requena Santos, Félix. Redes sociales y cuestionarios. Primera Edición. Madrid, 1996. 57p.

Tübert, Silvia. La muerte y lo imaginario en la adolescencia. Primera Edición, Madrid, Saltés. 1982.

Universitat de Barcelona, Departament de Sociología. "El centenario del suicidio, de Emile Durkheim". Seminario de fundamentos clásicos de la sociología, Programa de doctorado de sociología avanzada. 1999, pp. 39-72.

Villasante, Tomás. "Algunas diferencias para un debate creativo: abriendo una nueva etapa para el Network Analysis". En: Política y Sociedad, Nro. 33, Madrid, 2000, pp. 81-95.

Wellman, Barry. "El análisis estructural: del método y la metáfora a la teoría". En: Política y Sociedad. Madrid, 2000, Nro. 33, pp. 15-35.

The CQ Researcher. Youth Suicide. Volumen 14, Nro. 6, 2004, pp. 125-148. Disponible en $<w w w . t h e c q r e s e a r c h e r . c o m>$ 
